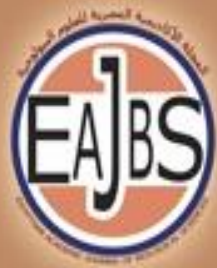

EGYPTIAN ACADEMIC JOURNAL OF
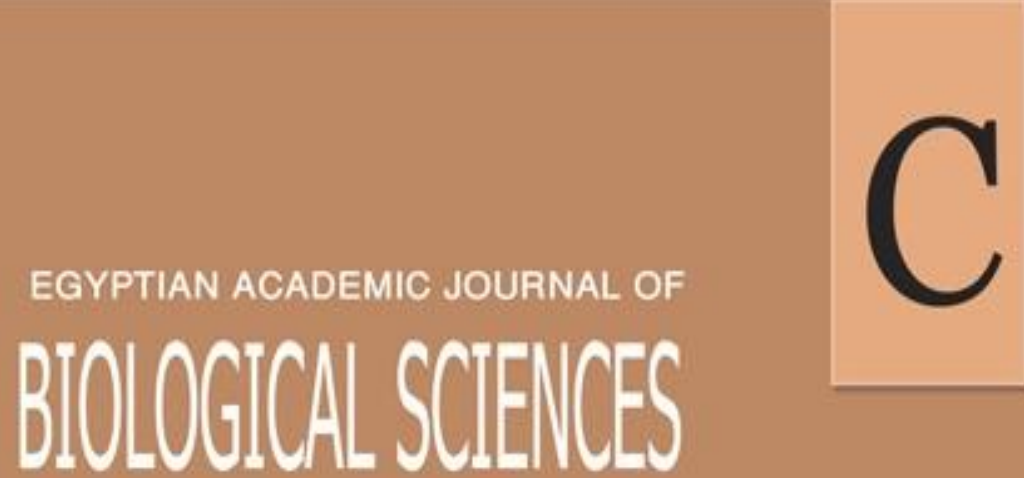

PHYSIOLOGY \& MOLECULARBIOLOGY
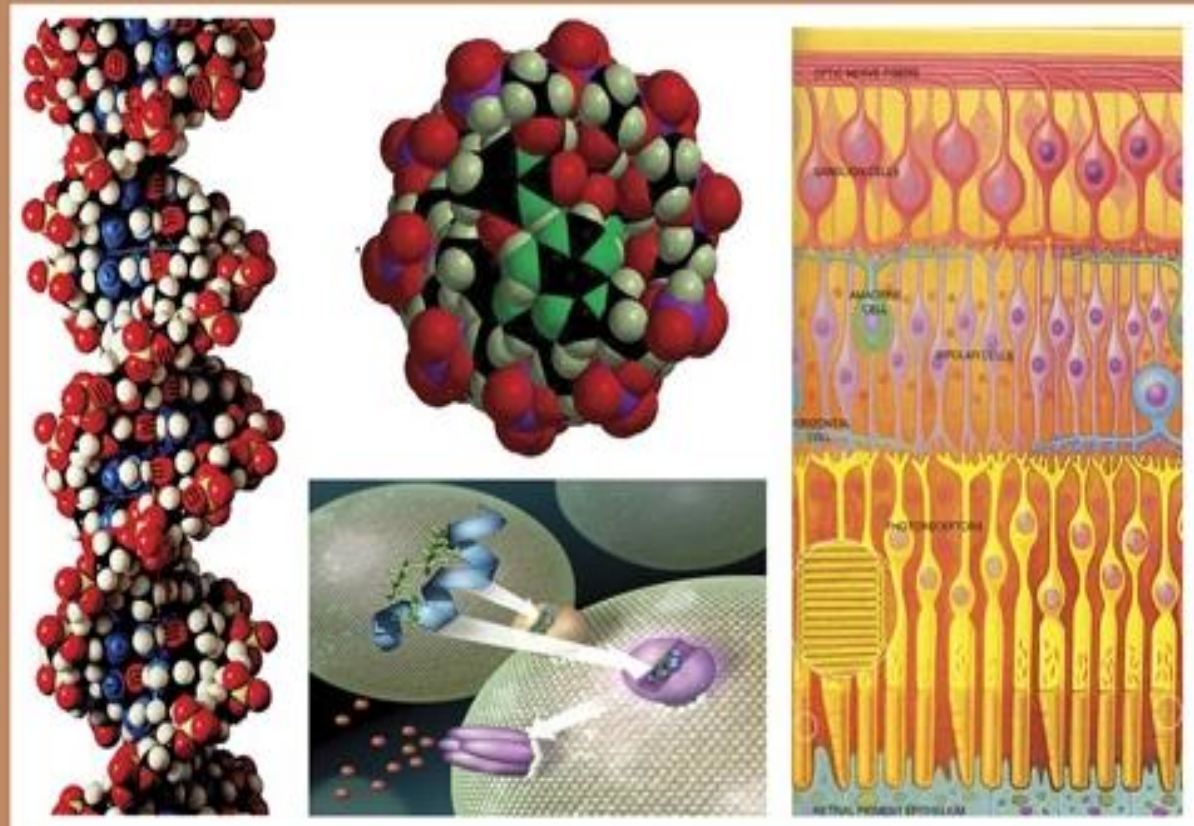

ISSN

2090-0767

WWW.EAJBS.EG.NET

Vol. 13 No. 2 (2021) 
Egypt. Acad. J. Biolog. Sci., 13(2):177-188 (2021)

Egyptian Academic Journal of Biological Sciences

C. Physiology \& Molecular Biology

ISSN 2090-0767

www.eajbsc.journals.ekb.eg

Magnesium, A Key Element for The Management of Hypertension, Cardiovascular Complications, Retinopathy, and Diabetic Foot in Diabetes

\author{
Nasr Eddine Kebir'1, Touria Zahzeh ${ }^{1}$, Meghit Boumediene Khaled ${ }^{2}$ and Mustapha \\ Diaf ${ }^{2}$ \\ 1-Laboratory of Molecular Microbiology, Proteomics and Health, Djillali Liabes \\ University of Sidi Bel Abbes, Algeria \\ 2-Department of Biology, Faculty of Natural and Life Sciences, Djillali Liabes \\ University of Sidi-Bel-Abbes, Sidi Bel Abbes, Algeria
}

*E. Mail : higher66@hotmail.fr

\section{REVIEW INFO}

Review History

Received:2/10/2021

Accepted:5/11/2021

\section{Keywords:}

Magnesium,

Diabetes,

hypertension, cardiovascular complications, retinopathy, diabetic foots

\section{ABSTRACT}

Magnesium is an alkaline earth metal, the eighth-most abundant mineral in the earth's crust. Most of the magnesium in the human body is found in the skeleton and teeth, at least $60-65 \%$ of the total. Almost all of the remaining amount is in tissues and muscle cells, while only $1 \%$ is in our blood. The balance of magnesium in the body is controlled by a dynamic interaction between intestinal absorption, exchange with bones, and renal excretion.

It fulfills many biological functions, including Activating muscles and nerves, creating energy in the body by activating adenosine triphosphate (ATP), helping to digest proteins, carbohydrates, and fats, serving as the building block for the synthesis of RNA and DNA.

Deficiencies in Mg status, including both hypomagnesemia and/or reduced $\mathrm{Mg}$ dietary intake, have been linked to an increased risk of a wide range of chronic diseases and strongly associated with developing DM2 or glucose intolerance, insulin resistance, and decreased insulin secretion.

Maximizing magnesium status through diet and supplementation appears to be a safe and useful way to stabilize and maintain adequate glucose levels and plays an important therapeutic and preventive role in diabetes and its complications.

\title{
INTRODUCTION
}

Magnesium is the eighth most common element in the crust of the Earth (Jahnen Dechent and Ketteler, 2012).

Magnesium $(\mathrm{Mg} 2+)$ is the fourth most common mineral in the human body, after calcium $(\mathrm{Ca} 2+)$, potassium $(\mathrm{K}+)$, and sodium $(\mathrm{Na}+)$, and the second most abundant intracellular cation after $\mathrm{K}+$ (Kolte et al., 2014).

Magnesium fulfills various intracellular physiological functions and has been recognized as a cofactor for $>300$ metabolic reactions in the body (Piovesan et al., 2012; Abdullah et al., 2018). 
Magnesium also plays a critical role in nerve transmission, cardiac excitability, neuromuscular conduction, muscular contraction, vasomotor tone, blood pressure, and glucose and insulin metabolism (Volpe, 2016)

The normal adult body content is approximately $20-25 \mathrm{~g}$ and its distribution is between 60 to $70 \%$ in bones, 25 to $30 \%$ in muscles, 6 to $8 \%$ in soft tissues, and $1 \%$ in the extracellular fluid (Naithani et al., 2014).

Deficiencies of $\mathrm{Mg}$ status including both hypomagnesemia and/or reduced dietary $\mathrm{Mg}$ intake have been linked to an enhanced risk to develop DM2 or glucose intolerance, insulin resistance, and decreased insulin secretion (Barbagallo and Dominguez, 2015; Milagros et al., 2005)

Measuring total magnesium in serum is a convenient and affordable way to monitor changes in the state of magnesium, but it does not necessarily reflect the body's total magnesium content (Costello et al., 2016; Costello et al., 2016).

The recommended dietary reference intake is about $301-420 \mathrm{mg} /$ day (Odusan et al., 2017).

\section{Magnesium and Hypertension:}

Hypertension is defined as systolic blood pressure $\geq 140 \mathrm{mmHg}$ or diastolic blood pressure $\geq 90 \mathrm{mmHg}$ is an extremely common condition in diabetes, affecting 20-60\% of patients with diabetes (Anwer et al., 2011), with diabetes, with the prevalence depending on type and duration of diabetes, age, sex, race/ethnicity, BMI, history of glycemic control, and the presence of kidney disease, among other factors (Ian et al., 2017).

Hypertension may precede the onset of diabetes mellitus (DM) and in about $95 \%$ of cases, it is essential hypertension and the rest may be secondary type. In some cases, both hypertension and diabetes mellitus may be present at the time of initial diagnosis.
Hypertension may develop later in a diabetic subject as a feature of diabetic nephropathy (Arya, 2003).

On the other hand, hypertension, a clinical entity in which insulin resistance is common, is strongly associated with a higher risk of developing metabolic complications, including new-onset diabetes, as compared to normotension, and it may precede the development of diabetes by several years (Volpe et al., 2015).

Magnesium is involved in blood pressure regulation. Every modification of the endogenous magnesium status leads to changes in vascular tonus and, as a consequence, changes in arterial blood pressure (Ueshima, 2005). Research over the decades has highlighted the crucial role of magnesium intake in the regulation of blood pressure and hypertension (Nguyen et al., 2013). A substantial body of epidemiological and experimental research is linking magnesium deficiency and cardiovascular diseases such as hypertension, atherosclerosis, and stroke (Kieboom et al.,2016; Rosique-Esteban et al., 2018).

Magnesium plays a critical role in maintaining normal nerve and muscle function, cardiac excitability (normal heart rhythm), neuromuscular conduction, muscular contraction, vasomotor tone, normal blood pressure (Gröber et al, 2015).

High $\mathrm{Mg}$ intake is associated with a lower risk of major cardiovascular (CV) risk factors (mainly metabolic syndrome, diabetes, and hypertension), stroke, and total cardiovascular disease (CVD). Higher levels of circulating $\mathrm{Mg}$ are associated with a lower risk of CVD, mainly ischemic heart disease and coronary heart disease, and stroke (Fang et al., 2016).

Magnesium deficiency increases angiotensin II-mediated aldosterone synthesis and the production of thromboxane and vasoconstrictor 
prostaglandins (Kostov and Halacheva 2018).

Insulin stores magnesium, but if the cell receptors are blunted and the cells grow resistant to insulin, the body can't store magnesium, so it passes out of the body through urination. If the magnesium level is too low, the smooth muscle of the blood vessels will be unable to fully relax, and this constriction raises blood pressure (hypertension) (Seriki, 2017).

Additionally, inflammation from magnesium deficiency can also lead to increased production of reactive oxygen species, which can contribute to elevating blood pressure (Nielsen, 2018).

Chronic dietary magnesium deficiency causes elevated blood pressure; initially, a hypotension phase is observed, which is due to the release of inflammatory agents, the subsequent hypertension is a result of oxidative stress and structural modifications in the vascular system (Rayssiguier et al., 2010).

Magnesium deficiency may contribute to the progression of atherosclerosis by its effects on lipid metabolism, platelet aggregation, and blood pressure, also characterized by increased triglycerides, cholesterol, verylow-density lipoprotein (VLDL), lowdensity lipoprotein (LDL), apolipoprotein $\mathrm{B}$, and triglyceride-rich lipoproteins, and a reduced High-density lipoprotein (HDL), apolipoprotein A1 and plasma lecithincholesterol acyltransferase activity (Swaminathan,2003).

Concomitant magnesium deficiency aggravates hypokalemia and renders it refractory to treatment by potassium. It is estimated that more than $50 \%$ of clinically significant hypokalemia has concomitant magnesium deficiency (Huang and Kuo, 2007).

Magnesium is a potent vasodilator of uterine and mesenteric arteries, and aorta, but has minimal effect on cerebral arteries. In vascular smooth muscle, magnesium competes with calcium for binding sites, in this case for voltageoperated calcium channels (VOCC). Decreased calcium-channel activity lowers intracellular calcium, causing relaxation and vasodilatation (Fig. 1) (Geiger and Wanner, 2012; Euser and Cipolla, 2009).

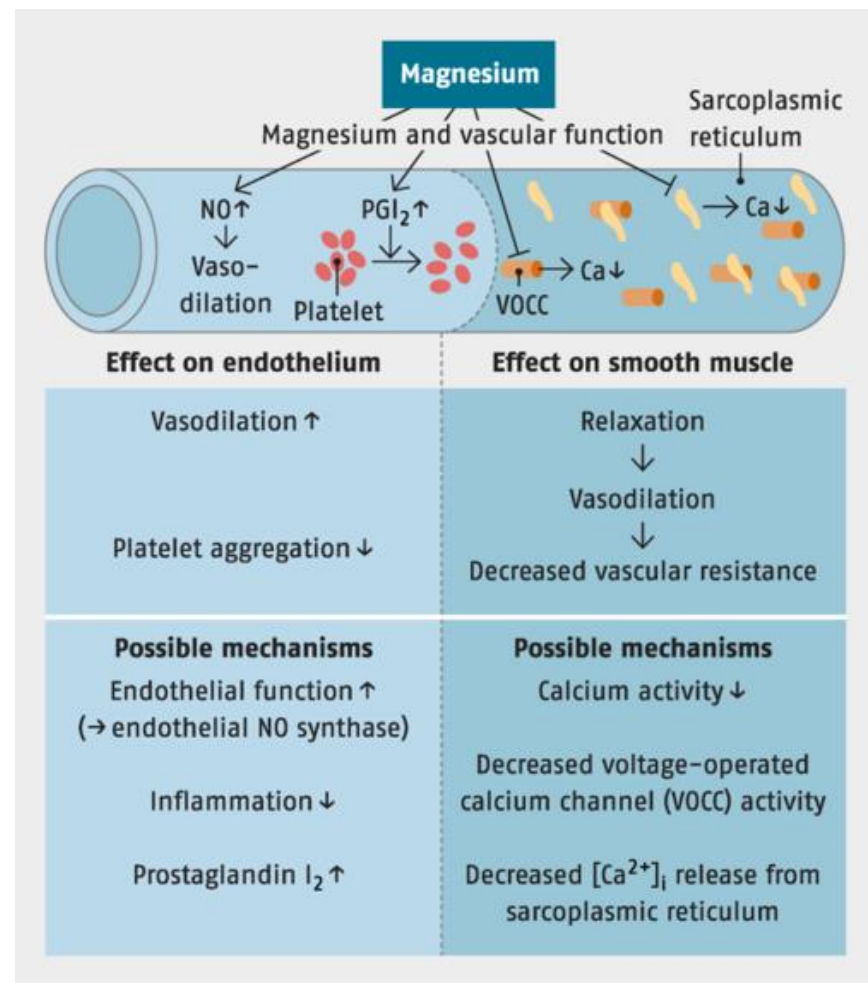

Fig.1. Magnesium and vascular function 
Magnesium deficiency has been shown to decrease the activity of the Na+$\mathrm{K}+$ pump, leading to an increase in intracellular sodium and calcium, which alters the membrane potential and increased peripheral resistance, and vasospasm (DiNicolantonio,2018; Purvis and Movahed, 1992).

At the tubular level, insulin has been found to stimulate $\mathrm{Na}+, \mathrm{K}+$-ATPase activity, increase sodium transport in proximal tubules, and potentiate the antinatriuretic effects of angiotensin II (Féraille et al.,1999).

Glucose-induced antinatriuresis is probably due to both enhanced glucosesodium co-transport and enhanced sodium reabsorption in the proximal tubules during hyperglycemia (Jaitovich and Bertorello,2010).

Compensatory hyperinsulinemia in insulin-resistant patients may alter the renal set point for sodium reabsorption by imposing a chronic antinatriuretic driving force on the kidney (enhanced by angiotensin II) and therefore play a critical role in the development and maintenance of high blood pressure (Horita et al., 2011).

Experiments in animals have also shown increased production of prostacyclin and nitric oxide (NO) by magnesium, promoting endotheliumindependent and endothelium-dependent vasodilation (Cunha et al.,2012).

Magnesium may have a protective effect against atherosclerosis and could play a role in promoting the growth of collateral vessels in chronic ischemia. Moreover, because it induces the synthesis of nitric oxide, this cation could be a helpful tool in hypertension as well as in preventing thrombosis (Maier et al., 2004).

Hypomagnesemia selectively impaired the release of nitric oxide from the coronary endothelium. Because nitric oxide is a potent endogenous nitrovasodilator and inhibitor of platelet aggregation and adhesion, hypomagnesemia could promote vasoconstriction and coronary thrombosis (Pearson et al., 1998).

Hypomagnesemia could inhibit the protective vasodilatory and thrombolytic action of the radical in the coronary circulation and put the blood vessels at risk for ischemic events such as vasospasm and thrombosis (Severino et al.,2019).

In addition, alterations in calcium and magnesium metabolism have been implicated in the pathogenesis of primary hypertension (Sontia and Touyz, 2007). The influx of calcium through the outer cell membrane into smooth muscle cells and cardiomyocytes plays a crucial role in controlling the contraction of cell excitation and pulse propagation. Intracellular calcium and magnesium concentrations are controlled by reversible binding to specific calcium-binding proteins (Kosch et al., 2001).

Calcium and magnesium fluxes through the outer membrane are regulated by calcium pump (calcium-magnesiumATPase), calcium channels, and membrane binding. The cell membranes and lymphocytes of hypertensive patients showed a significant increase in calcium, a decrease in magnesium, and an increased calcium/magnesium ratio $(\mathrm{Ca} 2+/ \mathrm{Mg} 2+>$ 2) (Kisters et al., 2004).

\section{Magnesium \\ Cardiomyopathy:} and

Patients with diabetes are at high risk of developing major cardiovascular complications, mostly including myocardial infarction, ischemic stroke, and congestive heart failure, but also microvascular complications, such as retinopathy, nephropathy, and peripheral artery disease (Kannel and McGee,1979).

Moreover, the presence of diabetes not only increases the risk of experiencing major cardiovascular events but also increases the risk of developing hypertension (Leon and Maddox, 2015).

Hypomagnesaemia is associated with hypokalemia, which causes cardiac 
arrhythmias (Van de Wal-Visscher et al., 2018).

Intracellular magnesium deficiency may also cause an increase in intracellular sodium and calcium which induce pathophysiological disorders in the cardiovascular system such as vasospasm, increased vasoconstrictor activity, elevation in smooth muscle and cardiac intracellular calcium concentration, formation of oxygen radicals, proinflammatory agents, and growth factors, and changes in membrane permeability and transport (Chetan et al.,2002).

A protective role of magnesium in calcification may underlie previous observations of higher magnesium intake and lower risk of stroke, nonfatal myocardial infarction (MI), sudden cardiac death, and fatal coronary heart disease (CHD) (Hruby et al., 2013).

Magnesium has vasodilatory, antiinflammatory, anti-ischemic, and antiarrhythmic properties; thus, it is presumably a useful therapeutic agent in cardiovascular medicine (MuñozCastañeda, 2018).

Proposed mechanisms for the potential cardiovascular benefits of magnesium intake include improvement of glucose and insulin homeostasis or lipid metabolism; his actions as an antihypertensive, anti-dysrhythmic, antiinflammatory, or anticoagulant agent; its antiplatelet effects; its effect on reduced vascular contractility and/or increased endothelial-dependent vasodilatation. Magnesium could lower blood pressure by acting as a calcium antagonist on smooth muscle tone, causing vasorelaxation (Houston, 2011; Watson, 2013).

Reduction in dietary magnesium intake and low magnesium in drinking water have been identified as risk factors for the development of hypertension, atherosclerosis, vasospasm, inflammatory conditions, and sudden cardiac death (Long and Romani,2014).

Magnesium and Diabetic Retinopathy: Diabetes retinopathy (DR) the most common microvascular complication to cause severe vision loss and blindness and a devastating effect on the quality of life and it takes into account mental and social impact, remains a global health issue According to the World Health Organization (WHO), it is estimated that DR accounts for $4.8 \%$ of the number of cases of blindness (37 million) worldwide (Yau et al., 2012; Ting et al.,2016; Duh et al., 2017; Pereira et al.,2017).

The prevalence of DR increases with the prolonged duration of diabetes (Cade, 2008).

The coexistence of hypertensive retinopathy and diabetic retinopathy further magnifies the risk of vision loss (Long and Dagogo-Jac, 2011). Patients with diabetic retinopathy (DR) are 25 times more likely to become blind than non-diabetics (Singh et al., 2008).

Type 2 diabetes accounts for approximately 90 to $95 \%$ of all diagnosed cases of diabetes. Studies suggest that at the time of diagnosis, the typical patient with type 2 diabetes mellitus has diabetes for at least 4 to 7 years. 4 Among patients with type 2 diabetes mellitus, $25 \%$ are believed to have retinopathy, $9 \%$ nephropathy, and $8 \%$ neuropathy at the time of diagnosis (Saproo and Singh, 2017). Many types of research suggest that low serum magnesium is one of the additional risk factors for the development of microvascular complications in type 2 diabetes mellitus (Kochar and Shrotriya, 2018).

However, in addition to hyperglycemia, other factors, such as hypertension, dyslipidemia, hypomagnesemia, hemorheological changes, and increased urinary total protein levels have a remarkable influence on the severity and clinical course of diabetic retinopathy (DR) (Corcóstegui et al., 2017; Shah et al., 2018; Kundu et al., 2013).

Diabetic retinopathy (DR) is a microvascular complication that can affect the peripheral retina, the macula, or both 
and is a leading cause of visual disability and blindness in people with diabetes (Pandit and Sultana, 2012).

Diabetic retinopathy progresses from mild nonproliferative abnormalities, characterized by increased vascular permeability, to moderate and severe nonproliferative diabetic retinopathy (NPDR) (Fong et al., 2004). The severity of DR varies from the non-proliferative, which is the earlier form of retinopathy with microvascular injury characterized by microaneurysms, retinal hemorrhages, and capillary closure to the pre proliferative form characterized by the proliferation of new abnormal blood vessels on the retina or optic nerve, stimulated by angiogenic factors from ischemic retinal tissue Figure 2 (Shah and Chen 2011; Safi et al., 2014; Hewapathirana ,2012.

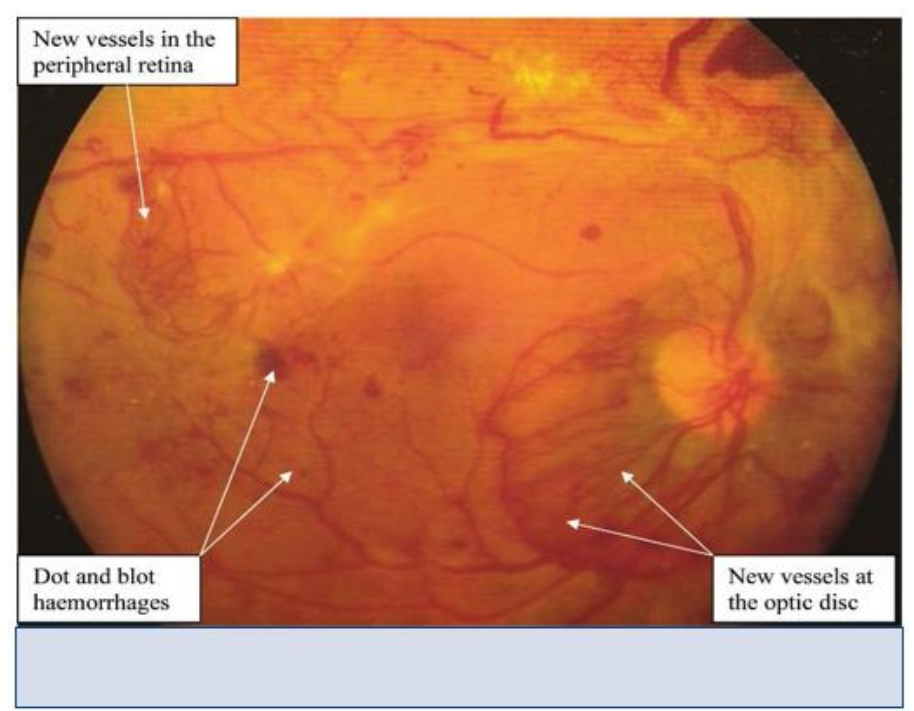

Fig. 2: Extensive new vessel formation both on the optic disc and the peripheral retina together with background dot and blot changes of background retinopathy and blot changes of background retinopathy. A small sub-hyaloid hemorrhage is seen in the top right of the retina at $12 \mathrm{o}$ clock relative to the optic disc.

Furthermore, magnesium deficiency is also a contributing factor in increased oxidative stress and inducible nitric oxide synthase (NOS) stimulation that can further contribute to the initiation and progression of ocular pathologies such as cataracts, glaucoma, and diabetic retinopathy (Agarwal et al., 2014).

Hypomagnesaemia is a possible risk factor in the development of advanced retinopathy and diabetic maculopathy. These might be related to the mechanism of maculopathy which depends on leakage of microaneurysm that increases with increasing endothelial cell damage (Navin et al., 2013; Haddad and Zuhair 2010; Ekici et al., 2014).

\section{Magnesium and Neuropathic Diabetic Foot Ulcers:}

The diabetic foot syndrome is defined as the detection of manifestations of peripheral nerve dysfunction includes several pathologies, mainly neuropathy, infection, microvascular dysfunction, and ischemia; acting together, they contribute to the sequence of tissue necrosis, ulceration, and gangrene (Amin and Doupi, 2016; Akbari and LoGerfo, 1999).

Among all possible complications of diabetes mellitus type 2, diabetic foot syndrome (DFS) is the leading reason for hospitalization. It is reported that up to $25 \%$ of diabetic subjects are at risk of developing diabetic foot ulcers (DFU) 
during their lifetime and poor wound healing is an important reason for morbidity and mortality (Volmer-Thole and Lobmann, 2016).

$\mathrm{Mg} 2+$ participates in many cellular functions, including energy production, synaptic neurotransmission, and intracellular signaling (Dribben et al., 2010).

Studies have shown a strong association between low levels of serum magnesium is significantly associated with an increased risk of T2DM and various complications such as diabetic foot ulcers. The possible mechanism suggested could be the association of hypomagnesemia and risk factors for the development of diabetic foot ulcers such as polyneuropathy and platelet dysfunction (Keşkek et al.,2013: Kauser et al., 2014; Phuong-Chi et al., 2007).

Studies postulate that serum magnesium levels may affect peripheral nerve function through axonal degeneration. First, there is growing evidence that magnesium can not only reduce the susceptibility of tissues to oxidative damage but also has indirect antioxidant capacity. In addition, it has been reported that magnesium can increase intracellular inositol levels by enhancing the affinity of the transport system for inositol, thus inhibiting further damage of the nervous system and a beneficial effect on peripheral nerve function in the patient with symptomatic diabetic neuropathy (Chu et al., 2016; Clements et al., 1979)

\section{Conclusion}

Over the last two decades, our understanding of the importance of $\mathrm{Mg} 2+$ ions for many cellular and body functions have increased significantly. Experimental evidence has been corroborated by the role of magnesium in clinical conditions such as diabetes and its complications. There is convincing evidence that increased consumption of nutrients containing a correct diet can help improve the quality of life by delaying and reducing the risk of metabolic diseases and, in particular, the development of diabetes.

The beneficial effects of ingestion or magnesium status on a multitude of metabolic disorders can be explained by several mechanisms, including improvement of glucose and insulin homeostasis, oxidative stress, lipid metabolism, vascular or myocardial contractility, endothelium-dependent vasodilatation, anti-arrhythmic effects, coagulant or antiplatelet and antiinflammatory effects. Studies have shown that adequate consumption of $\mathrm{Mg} 2+$ should be part of a healthy diet for diabetics.

Periodic determination of magnesium levels and magnesium supplementation may promote better glycemic control, a healthy lifestyle, and delay the onset of diabetes-related complications.

Longer-term prospective studies using similar amounts and types of magnesium supplementation are also needed to definitively establish a doseresponse effect and the best type of magnesium to use.

\section{REFERENCES}

Abdullah M. Al Alawi, Sandawana William Majoni, and Henrik Falhammar. 2018. Magnesium and Human Health: Perspectives and Research Directions, International Journal of Endocrinology, Article ID 9041694, 17 pages.

Agarwal R., Iezhitsa L., Agarwal P. 2014.Pathogenetic role of magnesium deficiency in ophthalmic diseases. Biometals, Volume 27, Issue 1, pp 5-18. doi. org/10.1007/ s10534-013-9684-5.

Akbari C.M., LoGerfo F.W. 1999.Diabetes and peripheral vascular disease. Journal of Vascular Surgery, 30(2):373-84.

Amin, N., \& Doupis, J.2016. Diabetic foot disease: From the evaluation of the "foot at risk" to the novel diabetic ulcer treatment modalities. World journal of diabetes, 7(7), 153-164. 
doi:10.4239/wjd. v7.i7.153.

Anwer Z., Sharma R.K., Garg V.K., Kumar N., Kumari A. Kumari. 2011.Hypertension management in diabetic patients. European Review for Medical and Pharmacological Sciences, 15: 1256-1263.

Arya S. N. .2003. Hypertension in Diabetic Patients - Emerging. Trends Journal, Indian Academy of Clinical Medicine, 4(2): 96-102.

Barbagallo M., Dominguez L.J. 2015.Magnesium and type 2 diabetes. World Journal of Diabetes, 6(10):1152-1157. doi:10. 4239/wjd. v6.i10.1152.

Cade W. T. 2008. Diabetes-related microvascular and macrovascular diseases in the physical therapy setting. Physical therapy, 88(11), 1322-35.

Chetan P. Hans, R. Sialy and Devi D. Bansal. 2002. Magnesium deficiency and diabetes mellitus. Current Science, Vol. 83, NO. 12, pp 1456- 1463, 2002.

Chou-Long Huang and Elizabeth Kuo.2007. Mechanism of Hypokalemia in Magnesium Deficiency. Journal of the American Society of Nephrology, 18: 2649 -2652. doi: 10.1681/ ASN.2007070792.

Chu, C. et al., 2016. Low serum magnesium levels are associated with impaired peripheral nerve function in type 2 diabetic patients. Science Reports, 6, 32623; doi: $10.1038 /$ srep32623

Clements, R. S. et al., 1979.Dietary myoinositol intake and peripheral nerve function in diabetic neuropathy Metabolism. Clinical and Experimental, Vol. 28, Issue 4, 477 $-483$.

Corcóstegui B., Durán S., GonzálezAlbarrán M.O., et al., 2017. Update on Diagnosis and Treatment of Diabetic Retinopathy: A Consensus Guideline of the Working Group of
Ocular Health (Spanish Society of Diabetes and Spanish Vitreous and Retina Society). Journal of Ophthalmology, 8234186. doi:10. 1155/2017/8234186

Costello R. B., Elin R. J., Rosanoff A. et al., 2016. Perspective: The Case for an Evidence-Based Reference Interval for Serum Magnesium: The Time Has Come, Advances in Nutrition, Volume 7, Issue 6, Pages 977-993, https://doi.org/10.3945/ an. 116.012765

Costello R., Wallace T.C., Rosanoff A.2016. Magnesium. Advances in Nutrition, 7(1):199-201. doi: 10.3 945/an.115.008524.

Cunha A.R., Umbelino B., Correia M.L., Neves M.F. 2012.Magnesium and vascular changes in hypertension. International Journal of Hypertension, 754250. doi:10.1155/2012/754250.

DiNicolantonio J.J., Liu J., O'Keefe J.H. 2018.Magnesium for the prevention and treatment of cardiovascular disease. Open Heart. 5: e000775. doi:10.1136/ openhrt-2018-000775.

Dribben, W. H., Eisenman, L. N., \& Mennerick, S. 2010. Magnesium induces neuronal apoptosis by suppressing excitability. Cell death \& disease, 1(8), e63. doi:10.1038 /cddis.2010.39.

Duh E.J., Sun J.K., Stitt A.W. 2017. Diabetic retinopathy: current understanding, mechanisms, and treatment strategies. JCI Insight, 2(14): e93751. doi: 10.1172/jci. insight.93751

Ekici F., Korkmaz S., Karaca E. E., et al., 2014. The Role of Magnesium in the Pathogenesis and Treatment of Glaucoma. International Scholarly Research Notices, vol. 2014, Article ID 745439, 7 pages. doi.org/10.1155/2014/745439.

Euser A.G., Cipolla M.J.2009. Magnesium sulfate for the treatment of 
eclampsia: a brief review. Stroke, 40(4):1169-1175. doi:10.1161/ STROKEAHA.108.527788

Fang X., Wang K., Han D., et al., 2016. Dietary magnesium intake and the risk of cardiovascular disease, type 2 diabetes, and all-cause mortality: a dose-response meta-analysis of prospective cohort studies. BMC Medicine, 14(1):210. doi:10.1186/ s12916-016-0742-z.

Féraille E., Carranza M.L., Gonin S., et al., 1999. Insulin-induced stimulation of $\mathrm{Na}+\mathrm{K}(+)$-ATPase activity in kidney proximal tubule cells depends on phosphorylation of the alpha-subunit at Tyr-10. Molecular Biology of the Cell, 10(9):2847-2859. doi:10.1091/ mbc.10.9.2847.

Fong D. S., Aiello L., Gardner T. W., G. L. King et al., 2004. Retinopathy in Diabetes. American Diabetes Association Diabetes Care, 27(suppl 1): s84s87 https://doi.org/ 10.2337/diacare.27. 2007.S84.

Geiger, H., and Wanner, C. 2012. Magnesium in disease. Clinical kidney journal, 5(Suppl 1), i25-i38.

Gröber U., Schmidt J., Kisters K. 2015.Magnesium in Prevention and Therapy. Nutrients, 23;7(9):8199226. doi: 10.3390/nu7095388.

Haddad N.S., Zuhair S. 2010. Serum Magnesium and Severity of Diabetic Retinopathy. The Medical Journal of Basrah University. Mjbu, VOL 28, No.1, p 35-39.

Hewapathirana N., Page S. 2012.Diabetic microvascular complicationsscreening, diagnosis and prevention. Rila Publications Ltd. Clinical Focus Primary Care, 6 (3): 177-191.

Horita S., Seki G., Yamada H., Suzuki M., Koike K., Fujita T. 2011.Insulin resistance, obesity, hypertension, and renal sodium transport. International journal of hypertension, 391762. doi:10. 4061
/2011/.

Houston M. 2011. The role of magnesium in hypertension and cardiovascular disease. Journal of Clinical Hypertens (Greenwich), 13:843-7.

Hruby, A., O'Donnell, C. J., Jacques, P. F., Meigs, J. B., Hoffmann, U., \& McKeown, N. M. 2013. Magnesium intake is inversely associated with coronary artery calcification: the Framingham Heart Study. JACC. Cardiovascular imaging, 7(1), 5969.

Ian H. de Boer, 2017. Sripal Bangalore, Athanase Benetos, Andrew $\mathrm{M}$. Davis, Erin D. Michos, Paul Muntner, Peter Rossing, Sophia Zoungas and George Bakris. Diabetes and Hypertension: $A$ Position Statement by the American Diabetes Association. Diabetes Care, 40(9): 1273 1284. doi.org/ 10.2337/dci17-0026.

Jahnen-Dechent, W., \& Ketteler, M. 2012. Magnesium basics. Clinical kidney journal, 5(Suppl 1), i3-i14. https:// doi.org/10.1093/ndtplus/sfr163

Jaitovich A., Bertorello A. M. 2010. Intracellular sodium sensing: SIK1 network, hormone action and high blood pressure. Biochimica et Biophysica Acta (BBA) - Molecular Basis of Disease, Vol. 1802, Issue 12, Pages 1140-11.

Kannel W.B., McGee D.L.1979. Diabetes and glucose tolerance as risk factors for cardiovascular disease: the Framingham study. Diabetes Care, 2(2):120-6.

Kauser M. M., Afreen A., Prabhakar K. and Jagadeesh K. 2014. Study of Serum Magnesium Levels in Diabetic Foot Ulcers-A South Indian Experience.International Research Journal of Medical Sciences, Vol. 2(9), 16-19.

Keşkek S.O., Kırım S., Karaca A., Saler T. 2013. Low serum magnesium levels and diabetic foot ulcers. 
Pakistan Journal of Medical Sciences, 29(6):1329-1333.

Kieboom B.C., Niemeijer M.N., Leening M.J., et al., 2016. Serum Magnesium and the Risk of Death from Coronary Heart Disease and Sudden Cardiac Death. Journal of the American Heart Association, 5(1): e002707. 22. doi:10.1161/ JAHA.115.002707.

Kisters K., Wessels F., Küper H., Tokmak F., Krefting E.R. et al.,2004. Increased calcium and decreased magnesium concentrations and an increased calcium/magnesium ratio in spontaneously hypertensive rats versus Wistar-Kyoto rats: Relation to Arteriosclerosis. 17(1):59-62.

Kochar A., Shrotriya R. 2018. Serum Magnesium Levels in Type II Diabetes Mellitus and Its Association with the Microvascular Complications. International Archives of Biomedical and Clinical Research (IABCR), 4(1):127-129.

Kolte, D.; Vijayaraghavan, K.; Khera, S.; Sica, D.A.; Frishman, W.H. 2014. Role of magnesium in cardiovascular diseases. Cardiology in Review, Volume 22, Number 4 (22), 182-192.

Kostov, K., and Halacheva, L. 2018. Role of Magnesium Deficiency in Promoting Atherosclerosis, Endothelial Dysfunction, and Arterial Stiffening as Risk Factors for Hypertension. International journal of molecular sciences, 19(6), 1724. doi:10.3390/ijms 19061724.

Kundu D., Osta M., Mandal T., Bandyopadhyay U., Ray D., Gautam D. 2013.Serum magnesium levels in patients with diabetic retinopathy. Journal of Natural Science, Biology and Medicine, 4(1):113-116. doi:10. 4103/0976-9668.107270.

Leon B.M., Maddox T.M. 2015. Diabetes and cardiovascular disease:

Epidemiology, biological

mechanisms, treatment

recommendations and future

research. World Journal of

Diabetes, 6(13):1246-1258. doi:10. 4239/wjd. v6.i13.1246

Long, A. N., \& Dagogo-Jack, S.2011. Comorbidities of diabetes and hypertension: mechanisms and approach to target organ protection. Journal of clinical hypertensio, 13(4), 244-51.

Long, S., \& Romani, A. M. 2014. Role of Cellular Magnesium in Human Diseases. Austin journal of nutrition and food sciences, 2(10), 1051.

Maier J.A., Bernardini D., Rayssiguier Y., Mazur A. 2004. High concentrations of magnesium modulate vascular endothelial cell behaviour in vitro. Biochimica et Biophysica Acta, 6 - 12.

Markus Kosch, Martin Hausberg, Gerald Westermann, Jens Köneke, Fritz Matzkies, Karl Heinz Rahn, Klaus Kisters. 2001. Alterations in calcium and magnesium content of red cell membranes in patients with primary hypertension. American Journal of Hypertension, Volume 14, Issue 3, Pages 254 258, https://doi.org/10.1016/S0895-7061 (00)01271-1.

Milagros G. Huerta, James N. Roemmich, Marit L. Kington et al., 2005. Magnesium Deficiency Is Associated with Insulin Resistance in Obese Children.Diabetes Care, Vol. 28, (5) pp 1175- 1181.

Muñoz-Castañeda, J. R., Pendón-Ruiz de Mier, M. V., Rodríguez, M., \& Rodríguez-Ortiz, M. E. 2018. Magnesium Replacement to Protect Cardiovascular and Kidney Damage? Lack of Prospective Clinical Trials. International journal of molecular sciences, 19(3), 664. doi:10. 3390/ 
ijms 19030664.

Naithani M., Bharadwaj J., Darbari A. 2014. Magnesium: The fifth electrolyte. The Journal of Medical Nutrition and Nutraceuticals (JMN N), 3:66-72.

Navin S., Krishnamurthy N., Ashakiran S., and Dayanand C.D. 2013.The association of hypomagnesaemia, high normal uricaemia and dyslipidaemia in the patients with diabetic retinopathy. Journal of clinical and diagnostic research, 7(9):1852-1854. doi:10.7860/ JCDR/2013/6106.3332

Nguyen, H., Odelola, O. A., Rangaswami, J., \& Amanullah, A. 2013. A review of nutritional factors in hypertension management.

International journal of hypertension, 698940. https://doi. org/10.1155/2013/698940

Nielsen F.H. 2018. Magnesium deficiency and increased inflammation: current perspectives. The Journal of Inflammation Research, 11:2534. doi:10.2147/JIR.S136742

Odusan O.O., Familoni O.B., Odewabi A.O., Idowu A.O., Adekolade A.S.2017. Patterns and correlates of serum magnesium levels in subsets of type 2 diabetes mellitus patients in Nigeria. Indian Journal of Endocrinology and Metabolism, 21:439-42.

Pandit J. \& Sultana Y. 2012. Vascular damage of retina in diabetic retinopathy and its treatment. Expert Review of Ophthalmology, 2; 7:1, 73-86, DOI: 10.1586/ eop. 11.81

Pearson P.J., Evora P.R., Seccombe J.F., $\begin{array}{lll}\text { Schaff } & \text { H.V. }\end{array}$ Hypomagnesemia inhibits nitric oxide release from coronary endothelium: protective role of magnesium infusion after cardiac operations. The Annals of Thoracic Surgery, Vol. 65, Issue 4, 967 972.
Pereira, D. M., Shah, A., D'Souza, M., Simon, P., George, T., D'Souza, N., Suresh, S., Baliga, M. S. 2017. Quality of Life in People with Diabetic Retinopathy: Indian Study. Journal of clinical and diagnostic research, JCDR 11(4), NC01-NC06.

Phuong-Chi T. Pham, Phuong-Mai T. Pham, Son V et al., 2007. Hypomagnesemia in Patients with Type 2 Diabetes.CJASN, 2 (2) 366373; DOI: $10.2215 / C J N .02960906$

Piovesan D., Profiti G., Martelli P.L., Casadio R. 2012.The human "magnesium": detecting magnesium binding sites on human proteins. BMC Bioinformatics, 13 Suppl 14(Suppl 14): S10. doi:10. 1186/1471-2105-13-S14-S10

Purvis J. R. and Movahed A. 1992. Magnesium disorders and cardiovascular diseases. Clinical Cardiology, 15,556-568.

Rayssiguier Y., Libako P., Nowacki W., Rock E. 2010. Magnesium deficiency and metabolic syndrome: stress and inflammation may reflect calcium activation. Magnesium Research,23 (2): 73-80

Ronald Ross Watson, Victor R. Preedy, Sherma Zibadi. 2012.Magnesium in Human Health and Disease Springer Science \& Business Media. 309 pages p105

Rosique-Esteban, N., Guasch-Ferré, M., Hernández-Alonso, P., \& SalasSalvadó, J. 2018. Dietary Magnesium and Cardiovascular Disease: A Review with Emphasis in Epidemiological Studies. Nutrients, 10(2), 168. https://doi.org/10.3390/nu1002016 8

Safi, S. Z., Qvist, R., Kumar, S., Batumalaie, K., \& Ismail, I. S.2014. Molecular mechanisms of diabetic retinopathy, general preventive strategies, and novel therapeutic targets. BioMed 
research international, 801269.

Saproo N., Singh R. 2017. Study of serum magnesium levels in diabetes mellitus and its correlation with complications (retinopathy and HbA1c) a cross-sectional study of one year.

Seriki A. S.2017. Salt, Glucose, and Hypertension: Interactions, Benefits and Risk. J Cardiol \& Cardiovasc Ther. 4(2): 555634. DOI: 10.19080/JOCCT.2017. 04. 555634005

Severino, P., Netti, L., Mariani, M. V., Maraone, A., D'Amato, A., Scarpati, R., Infusino, F., Pucci, M., Lavalle, C., Maestrini, V., Mancone, M., \& Fedele, F. 2019. Prevention of Cardiovascular Disease: Screening for Magnesium Deficiency. Cardiology research and practice, 4874921. https:// doi.org/10.1155/2019/4874921

Shah N. A., Amir M., Noreen L., Shah J.A. et al., 2018. Serum Magnesium Levels in Diabetic Retinopathy. Pakistan Armed Forces Medical Journa, 68 (4): 740-44.

Shah, C. P., \& Chen, C. 2011.Review of therapeutic advances in diabetic retinopathy. Therapeutic advances in endocrinology and metabolism, 2(1), 39-53.

Singh, R., Ramasamy, K., Abraham, C., Gupta, V., \& Gupta, A. 2008.Diabetic retinopathy: an update. Indian journal of ophthalmology, 56(3), 178-88.

Sontia. B and Touyz. RM. 2007. Magnesium transport in hypertension. Pathophysiology, Volume 14, Issues 3-4, Pages 205211.

Swaminathan R. 2003. Magnesium metabolism and its disorders.
Clinical Biochemist Reviews, 24 (2):47-66.

Ting D.S., Cheung G.C., Wong T.Y. 2016. Diabetic retinopathy: global prevalence, major risk factors, screening practices and public health challenges: a review. Clinical and Experimental Ophthalmology, 44: 260-277 doi: 10.1111/ceo.12696.

Ueshima K. 2005. Magnesium and ischemic heart disease: a review of epidemiological, experimental, and clinical evidences. Magnesium Research, 18 (4): 275-84.

van de Wal-Visscher, E. R., Kooman, J. P., \& van der Sande, F. M. 2018. Magnesium in Chronic Kidney Disease: Should We Care? Blood purification, 45(1-3), 173-178. https://doi.org/10.1159/000485212

Volmer-Thole, M., \& Lobmann, R. 2016. Neuropathy and Diabetic Foot Syndrome. International journal of molecular sciences, 17(6), 917.doi:10.3390/ijms17060917

Volpe S. L.2013. Magnesium in disease prevention and overall health. Advances in nutrition, 4(3), 378S83S. doi:10.3945/an.112.003483.

Volpe S.L.2013. Magnesium in disease prevention and overall health. Advances in nutrition, 4(3):378S83S. doi:10.3945/an.112.003483

Volpe, M., Battistoni, A., Savoia, C., \& Tocci, G. 2015. Understanding and treating hypertension in diabetic populations. Cardiovascular diagnosis and therapy, 5(5), 35363.

Yau J.W., Rogers S.L., Kawasaki R., et al.,2012. Global prevalence and major risk factors of diabetic retinopathy. Diabetes Care, 35(3):556-64. 